\title{
Смертная казнь и право на жизнь
}

Семенов И.С. *

Статья посвящена современной ситуации с судебной практикой в отношении смертной казни в национальном и международном праве. На сегодняшний день единственным международным актом, прямо запрещающим ее применение, является Европейская конвенция о защите прав человека и основных свобод с дополнительными Протоколами № 6 и № 13. Автором предпринята попытка анализа текущей ситуации на основании решений Европейского суда по правам человека. Примечательно, что Суд до сих пор не имеет однозначной позиции в отношении рассматриваемого вопроса: является ли смертная казнь нарушением ст. 2 ЕКПЧ? В своих решениях Суд, как правило, соотносит возможность назначения и применения смертной казни с нарушением ст. 3 Конвенции, тогда как ст. 2 признается нарушенной лишь в нескольких специфических случаях по процедурным основаниям.

Ключевые слова: право на жизнь; смертная казнь; Европейская конвенция о защите прав человека и основных свобод; Европейский суд по правам человека; защита от жестокого обращения, экстрадиция.

Право человека на жизнь закреплено в законодательстве подавляющего большинства государств, а также в ряде международно-правовых актов универсального и регионального характера. Вместе с тем оно является едва ли не самым нарушаемым. При этом помимо огромного количества преступлений против жизни и здоровья человека имеются случаи, когда он лишается жизни волей государства в наказание за совершенные преступления. По данным международной правозащитной организации Amnesty International, в период с января по декабрь 2008 года в 25 странах мира казнили не менее 2390 человек; в 52 странах к исключительной мере наказания приговорили по меньшей мере 8864 человека ${ }^{1}$. При этом мнения о целесообразности применения смертной казни в качестве наказания и влиянии этой

\footnotetext{
* Семенов Иван Сергеевич - аспирант Дипломатической академии МИД России. i-semenov@inbox.ru.

${ }^{1}$ По данным официального сайта организации на 24.03.2009 г. Примечательно, что эти показатели демонстрируют значительный рост по сравнению с 2007 годом, когда, по данным той же организации, были казнены по меньшей мере 1252 человека в 24 странах и приговорены к смертной казни не менее 3347 человек в 51 стране.
} 
меры на состояние преступности в стране и обществе крайне неоднозначны. Это лишний раз демонстрирует противоречивость складывающейся в мире ситуации.

В связи с этим необходимо отметить особую роль судов в формировании как теоретической, так и практической точки зрения на исключительную меру наказания. В зависимости от системы права решение суда может являться официальным толкованием той или иной нормы или даже стать нормой как таковой. Более того, в связи с отсутствием глобального документа, касающегося особенностей назначения и применения смертной казни, а также ее правового статуса в отношении права на жизнь, решения национальных и международных судов зачастую становятся de facto единственным источником правовых норм в отношении данной проблемы. К сожалению, объем статьи не позволяет в полной мере рассмотреть все аспекты данного вопроса. В связи с этим в данной статье хотелось бы уделить особое внимание деятельности Европейского суда по правам человека (далее - Суд, ЕСПЧ), важная роль которого в толковании смертной казни и ее соотношения с правом на жизнь не вызывает сомнений.

Европа уже давно является зоной, фактически свободной от исключительной меры наказания. Именно здесь запрет применения смертной казни приобрел юридический характер с принятием Протокола № $6^{2}$ к Европейской конвенции о защите прав человека и основных свобод (далее - ЕКПЧ) 1950 года. Государства - участники Протокола № 6, равно как и те, которые имели желание вступить в Совет Европы, должны были отказаться от применения исключительной меры наказания. Впрочем, положение, предусмотренное ст. 2 данного Протокола, предоставляет государству - участнику данного Протокола право «предусмотреть в своем законодательстве смертную казнь за действия, совершенные во время войны или при неизбежной угрозе войны». Впоследствии это положение было исключено Протоколом № $13^{3}$ к ЕКПЧ, отменившим смертную казнь при любых обстоятельствах. Нельзя не обратить внимания, что страны - участники данных соглашений стремятся не только не допустить применения смертной казни в самой Европе, но и во многих случаях выступают гарантом неприменения исключительной меры

2 Принят 28.04.1983, вступил в силу 01.03.1985. Россия подписала данный Протокол 16 апреля 1997 г.

3 Принят 03.05.2002, вступил в силу 01.07.2002. Россия не подписала и не ратифицировала данный Протокол. 
к лицам, выдаваемым в страны, не являющиеся участниками указанных соглашений. С одной стороны, это является необходимым для соблюдения требований ЕКПЧ (а также ст. 11 Европейской конвенции о выдаче), с другой - дополнительно гарантирует безопасность лиц, имеющих шанс быть осужденными на смерть.

Между тем на сегодняшний день одним из наиболее важных неразрешенных вопросов теории и практики остается позиция Суда по вопросу соотношения смертной казни со ст. 2 ЕКПЧ. В соответствии с данной статьей «никто не может быть умышленно лишен жизни иначе как во исполнение смертного приговора, вынесенного судом за совершение преступления, в отношении которого законом предусмотрено такое наказание». Вместе с тем последующие документы уже упомянутые выше Протоколы № 6 и № 13 - внесли дополнения в ЕКПЧ, фактически запретив смертную казнь в государствах - участниках конвенции и Протоколов к ней. Данные поправки вместе с тем не означают, что смертная казнь автоматически признается нарушением права на жизнь. Как отмечает А.Б. Мезяев, общая оценка ст. 2 ЕКПЧ, напротив, сводится к тому, что она не имеет своей целью безусловную защиту жизни как таковой 4 . Действительно, большая часть дел, касающихся возможности применения смертной казни, рассматривается не столько в рамках ст. 2, сколько во взаимосвязи со ст. 3 конвенции. То есть речь идет не столько о самой процедуре исполнения приговора и лишении человека жизни, сколько об ожидании его исполнения, пребывании в особых условиях заключения (так называемый феномен death row), возможности экстрадиции в страну, где смертная казнь допускается законом и т.д. ${ }^{5}$ В этом контексте наиболее показательным является хорошо известное юристам дело «Соринг против Соединенного Королевства», когда Европейский суд признал, что в случае выдачи гражданина Соринга Соединенным Штатам Великобритания нарушила бы именно ст. 3 ЕКПЧ. В этом случае заявитель указывал, что «разделяет мнение Комиссии, что сама по себе выдача лица стране, в которой существует риск вынесения ему смертного приговора, не позволяет говорить о нарушении ни ст. 2 , ни ст. $3{ }^{\prime} 6$, обращая,

\footnotetext{
4 Мезяев А.Б. Проблема смертной казни в региональном международном праве //. Московский журнал международного права. № 2/2001. С. 126.

5 Там же. С.128.

6 Абз. 3 пара. 101 Решения ЕСПЧ по делу «Соринг против Соединенного Королевства» от 07.07.1989.
} 
однако, особое внимание на условия его ожидания и страдания, неизбежные в случае его выдачи. Соринг заявлял, что «те условия, в которые он будет поставлен в результате ... выдачи его Соединенным Штатам ... представляют собой плохое обращение такой степени тяжести, что его экстрадиция противоречит статье $3 »^{7}$. Он ссылался, в частности, на длительность процедуры рассмотрения жалоб, во время которой он будет испытывать все возрастающее психологическое напряжение, травмирующее психику, на экстремальные условия его будущего заключения в «камере смертников» в Мекленбургском исправительном центре, где, как он предполагал, мог стать жертвой насилия и сексуальных домогательств в силу его возраста, расовой и национальной принадлежности и прочих обстоятельств.

В конечном итоге Суд, с одной стороны, опосредованно признал право запрашивающего государства на назначение в качества наказания смертной казни, отметив, что «составители Конвенции не могли иметь намерения рассматривать статью 3 как включающую запрещение смертной казни вообще, поскольку это сводило бы на нет ясную формулировку статьи 2 п. $1 »^{8}$, допускающую лишение человека жизни по приговору суда. С другой - в параграфах 104 и 111 своего постановления Суд выразил свое мнение об ожидании смертной казни как о процедуре, причиняющей страдания и, соответственно, напрямую нарушающей ЕКПЧ. Во многом это было обусловлено состоянием самого подсудимого. Суд особо отметил, что, «учитывая значительную длительность времени нахождения в камере смертников в экстремальных условиях, в состоянии постоянной и все возрастающей подавленности в ожидании приведения в исполнение смертного приговора, а также учитывая личные обстоятельства заявителя, в особенности его возраст и психическое состояние в момент совершения преступления, выдача заявителя Соединенным Штатам означала бы для него реальный риск подвергнуться обращению, превышающему порог, установленный в статье 3 ». Важным также представляется и фактор ожидания экстрадиции с перспективой применения смертной казни. Довольно зыбкое осознание собственной безопасности является, как представляется, дополнительным фактором страданий лица.

На наш взгляд, однако, данная позиция Суда представляется не вполне однозначной. С одной стороны, данное решение все-таки

7 Там же. Абз. 1 пара. 105.

8 Там же. Абз. 1 пара. 103. 
установило определенный критерий для признания смертной казни (а точнее, процедуры ее назначения и приведения в исполнение) нарушением ст. 3 ЕКПЧ. Вместе с тем не секрет, что длительное ожидание, тем более нарастание напряженности по мере приближения исполнения приговора, имеет место практически всегда. Это обусловлено и «спецификой» данного наказания, и предусмотренными законом процедурами обжалования, также требующими времени, и особым статусом таких заключенных, что характеризуется помимо прочего особой охраной и условиями содержания в целом. Суд, однако, оговорил, что ст. 3 не может рассматриваться как исключающая применение смертной казни в целом (см. выше). Таким образом, налицо некоторая противоречивость ситуации. С одной стороны, по мнению Суда, ни ст. 2, ни ст. 3 не подразумевают трактовку смертной казни как нарушающей права человека в принципе. С другой - обстоятельства, неизменно сопутствующие ее назначению и применению, являют собой нарушение положений ЕКПЧ, причем положений ст. 3.

В этом случае и в дальнейшей практике Суда стало правилом требовать от государства, в которое должен быть передан заключенный, гарантии того, что он не будет приговорен к смертной казни. Примечательно, что тем самым Суд фактически сохранял заключенному жизнь, независимо от формальной оценки рассматриваемых статей.

Данное решение явилось своего рода прецедентом, оказавшим влияние на рассмотрение дел, касающихся возможного назначения исключительной меры наказания, в судах. Впредь дела, связанные с возможностью вынесения смертного приговора, рассматривались в непосредственной взаимосвязи не только со ст. 2, но и со ст. 3 ЕКПЧ. Заявители, в свою очередь, при подаче жалобы в случае назначения исключительной меры наказания (или угрозы такового) неизменно указывали и на факты нарушения ст. 3, сопровождающие процедуру приведения в исполнение данного наказания.

Подобные выводы содержались и в постановлениях Суда в отношении Российской Федерации. Одним из разбирательств, наиболее заметных в этом плане, являлось дело «Илашку и другие против Молдавии и Российской Федерации». К рассматриваемой теме имело отношение лишь положение самого И. Илашку, так как он единственный из заявителей, кто был приговорен к смертной казни, и состояние неопределенности в условиях неотмененной смертной казни было, по его словам, дополнительным фактором, причиняющим ему 
страдания. В связи с этим Суд подтвердил, что «каждый осужденный к смертной казни неизбежно ... испытывает сильный стресс в условиях полной изоляции ... В некоторых случаях за осуждением к смертной казни может последовать обращение, превышающее рамки, установленные ст. 3 Конвенции» ${ }^{9}$. В рассматриваемом случае в течение всего периода ожидания смертного приговора заявитель «жил в постоянном страхе за свою жизнь, в тени смерти» ${ }^{10}$. Он неоднократно был избиваем надзирателями, лишался пищи и света на несколько дней. Принимая во внимание эти факты, Суд сделал вывод, что «осуждение к смертной казни, вкупе с условиями жизни и обращением с ним во время заключения после ратификации Конвенции ... ввиду особой серьезности и жестокости должны быть признаны пыткой по смыслу ст. 3 Конвенции» ${ }^{11}$. В решении Суда особо указано, что обжалованные Илашку факты не требовали отдельного рассмотрения на предмет нарушения ст. 2 и должны были быть изучены именно в рамках ст. 3 ЕКПЧ 12.

Кроме того, данная позиция Суда была подкреплена и рядом решений по делам о возможной экстрадиции, в которых Российская Федерация выступала в качестве выдающей стороны. Так, в деле «Исмоилов и другие против России» речь шла о возможной выдаче заявителей российской стороной Узбекистану, где они могли быть приговорены к исключительной мере за преступления, для которых узбекское законодательство предусматривало смертную казнь в качестве меры наказания. В контексте данной статьи примечательно, что в соответствии с судебными документами первый заместитель Генерального прокурора Узбекистана дал гарантии, что «заявители не будут подвергнуты смертной казни, пыткам, насилию или иным формам бесчеловечного и унизительного обращения или наказания» ${ }^{13}$. То есть смертная казнь упоминается в «списке» других нарушений, относящихся непосредственно к ст. 3. Кроме того, Суд постановил, что «риск приговора заявителей к смертной казни [в результате ее отмены ${ }^{14}$ б был

\footnotetext{
9 Пара. 430 Решения ЕСПЧ по делу «Илашку и другие против Молдавии и Российской Федерации» от 08.07.2004.

10 Там же, пара. 435.

11 Там же, пара. 440.

12 Там же, пара. 417-418.

13 Пара. 31 Решения ЕСПЧ по делу «Исмоилов и другие против России» от 24.04.2008.

14 Смертная казнь отменена в Узбекистане с 1 января 2008 года.
} 
... устранен, в связи с чем никаких вопросов, требующих судебного разрешения, в контексте $\mathrm{cm} .3$ возникнуть не должно» 15 .

Необходимо отметить, что формулировки решений Суда, подобные приведенной в предыдущем абзаце, встречаются и в иных его решениях по данной тематике. Так, обязательство властей в случае выдачи «не подвергать заявителя пыткам, иному бесчеловечному или унизительному обращению или смертной казни» содержалось в судебном решении по делу «Муминов против России» ${ }^{16}$. Показательно также, что тексты обоих приведенных выше решений не содержат ни одной ссылки на ст. 2 конвенции, хотя речь идет, как указывалось, и о возможности применения к заявителям смертной казни.

Необходимо особо отметить ряд обстоятельств, сопутствующих разрешению данной ситуации. Прежде всего отметим, что на момент рассмотрения двух указанных выше дел Россия уже присоединилась к Европейской конвенции о выдаче 1957 года, которая, в частности, подразумевает возможность отказа в выдаче лица запрашивающей стороне в случае, если к нему может быть применена смертная казнь, если данное наказание не предусматривается законодательством выдающей стороны или оно не приводится в исполнение даже будучи назначенным. Учитывая же тот факт, что ко времени принятия решений по данным делам в России уже на протяжении длительного срока действовал фактический мораторий на смертную казнь (см. ниже), возможность выдачи запрашивающей стороне без соответствующих гарантий последней была по меньшей мере маловероятной. Более того, принимая во внимание отмену смертной казни в самой запрашивающей стране, разбирательство данного вопроса вообще теряло смысл.

Вместе с тем в определенных случаях смертная казнь может признаваться нарушением именно ст. 2 ЕКПЧ. Ярким примером подобной ситуации может быть позиция Суда по делу «Оджалан против Tyрции», окончательное решение по которому Суд вынес 12 мая 2005 года. Напомним: разбирательство по данному делу в национальных судах и Европейском суде по правам человека шло с 1999 года, когда лидер Курдской Рабочей Партии (КРП) предстал перед судом в Турции по обвинению в причастности к гибели более 30 тысяч человек, ставших жертвами конфликта между официальной властью и КРП. В том же году он был приговорен к смертной казни, однако приговор не был приведен

15 Там же, пара. 119.

16 См. пара 128 Решения ЕСПЧ по данному делу от 11.12.2008. 
в исполнение по целому ряду причин. Прежде всего, в 2002 году смертная казнь за любые преступления в мирное время была запрещена законом № 4771, после чего и была заменена для Оджалана на пожизненное заключение без права досрочного освобождения. Более того, 12 ноября 2003 года Турция ратифицировала Протокол № 6, что дополнительно защищало подсудимого от исполнения приговора.

Тем не менее Суд отметил, что «смертный приговор в отношении лица, вынесенный в ходе несправедливого разбирательства, подвергает лицо неправомерному страху быть казненным» ${ }^{17}$. Вместе с тем Большая Палата подтвердила, что по смыслу cm. 2 вынесение лицу смертного приговора по результатам несправедливого разбирательства недопустимо и является нарушением таковой. Отметим также, что заявитель указывал в первую очередь именно на нарушение положений ст. 3, обращая внимание, в частности, на решения ряда национальных судов, признавших приведение в исполнение смертного приговора жестоким актом, нарушающим положения данной статьи ${ }^{18}$.

Аналогичная ситуация была рассмотрена ЕСПЧ в рамках разбирательств по делу «Бадер и Канбор против Швеции». Заявители, сирийские граждане, протестовали против решения шведского суда в отношении их депортации в Сирию. При этом они утверждали, что их передача сирийским властям явится нарушением ряда статей ЕКПЧ, в частности ст. 2. Напомним: первый заявитель был признан сирийским судом в организации убийства, а также незаконном владении оружием, и заочно приговорен к смертной казни в соответствии со ст. 535 Уголовного кодекса Сирии. Правительство Швеции, признавая, что «ситуация с правами человека в Сирии все еще проблематична, отмечая, помимо прочего, возможность назначения смертной казни, среди других преступлений, за убийство» ${ }^{19}$, заявило, однако, что, поскольку детали применения смертной казни никогда не были достоянием общественности, трудно определить, имеет ли место исполнение приговоров на практике. Кроме того, судебная система Сирии предлагает обвиняемым возможности для оспаривания решений, которыми заявитель не воспользовался.

17 Пара. 169 Окончательного решения ЕСПЧ по делу «Оджалан против Турции» от 12.05.2005.

18 Там же, пара. 159.

19 Пара. 38 Окончательного решения ЕСПЧ по делу «Бадер и Канбор против Швеции» от 08.02.2006. 
Вместе с тем информация о том, что реальные обстоятельства применения смертной казни в Сирии неизвестны, равно как сомнения в том, будет ли процесс возобновлен при передаче заявителя сирийским властям для апелляции, являлись в равной степени свидетельствующими о возможном риске для заявителя подвергнуться смертной казни. В результате Суд признал, что «заявитель имеет справедливые и обоснованные опасения, что смертный приговор в его отношении будет приведен в исполнение в случае, если он будет возвращен на родину» ${ }^{20}$. При этом в более ранних решениях отмечалось, что, в то время как само по себе стремление государства депортировать лицо, незаконно находящееся на его территории, оправданно и законно, допустимо наступление ответственности выдающей стороны по ст. 3 конвенции в случае, если выдаваемое лицо имеет основание полагать, что будет подвергнуто обращению, нарушающему нормы данной статьи ${ }^{21}$. Суд особо отметил и то, что в более ранних разбирательствах не исключалась возможность привлечения договаривающейся стороны к ответственности и по ст. 2 ЕКПЧ, а также ст. 1 Протокола № 6 к ней в случае выдачи лица государству, где оно будет иметь серьезные основания быть казненным. Вместе с тем Суд указывал, что «Большая Палата воздержалась от заключения по вопросу, может ли статья 2 Конвенции считаться измененной [после принятия Протокола № 13 к Конвенции] как запрещающая смертную казнь при любых обстоятельствах» ${ }^{22}$. В связи с этим Суд упоминал решение по приведенному выше делу Оджалана, в котором особое внимание также было уделено возможности нарушения ст. 2 ЕКПЧ при назначении смертной казни в результате несправедливого судебного разбирательства, чего также нельзя было исключать и в данном случае. В результате Суд пришел к выводу, что экстрадиция (хотя, возможно, в данном случае уместнее было бы сказать «возвращение») заявителя в Сирию для дальнейшего судебного разбирательства явилось бы нарушением как ст. 3, так и ст. 2 ЕКПЧ. Данное дело послужило также очередным подтверждением позиции Суда в отношении возможной экстрадиции обвиняемых в запрашивающую страну, где существует риск быть казненным. В этом плане наиболее эффективным судебным инструментом, закрепленным на практике еще в деле Соринга, стало требование определенных гарантий

20 Там же, Пара. 46.

21 См., напр., пара. 34 Решения ЕСПЧ по делу «H.L.R. v. France» от 29.04.1997.

22 Там же, абз. 4 пара. 42. 
запрашивающей стороны о неприменении в отношении обвиняемого смертной казни. Вместе с тем дополнительным фактором, как в указанных выше делах против России, является и сложившаяся в данный момент практика по делам о смертной казни, а также и правовой статус исключительной меры наказания в данный момент в юрисдикции запрашивающей или, как в последнем случае, «принимающей» стороны. Заметим, однако, что, невзирая на принятие большинством стран Европы Протокола № 13, Суд по-прежнему воздерживается от вынесения конкретного заключения по данной проблематике.

Однако, на наш взгляд, особое место в текущей практике Европейского суда занимает тема назначения и применения исключительной меры наказания в Российской Федерации. Стоит напомнить, что одним из условий вступления России в Совет Европы являлось именно немедленное установление моратория на исполнение смертных приговоров, о чем недвусмысленно говорилось, в частности, в рекомендации ПАСЕ 23 , на основании которой Комитет министров и пригласил Россию в Совет. Приглашенной стороне при этом отводилось три года на ратификацию Протокола № 6. Однако на сегодняшний день данный Протокол по-прежнему не ратифицирован Российской Федерацией. Вместе с тем, хотя Уголовный кодекс России по-прежнему предусматривает смертную казнь в качестве наказания за особо тяжкие преступления, на практике оно не применялось с 1996 года. При этом, как отмечает Б.Р. Тузмухамедов, существует устойчивое заблуждение, что основанием возникновения данного моратория является Указ Президента РФ от 16 мая 1996 года «О поэтапном сокращении применения смертной казни в связи с вхождением России в Совет Европы», тогда как данный акт «содержит, самое большее, нормативное предположение» ${ }^{24}$. По мнению данного автора, комплексный мораторий на назначение смертной казни и приведение ее в исполнение основывается, во-первых, на принятии приглашения СЕ, подразумевающего стремление России соблюдать условия «действительности» данного соглашения, свидетельством чего является, в частности, подписание со стороны РФ Протокола № 6, и, во-вторых, на хорошо известном Постановлении КС РФ № 3-П от 2 февраля 1999 года, касающемся конституционного права на суд с участием присяжных заседателей

23 Пп. іi п. 10 Заключения ПАСЕ No.193 (1996) от 25.01.1996.

${ }^{24}$ Б.Р. Тузмухамедов. Отмена смертной казни в России: международные обязательства и конституционная юрисдикция // Международное право. № 4/2008. С. 57. 
и, как следствие, невозможностью назначения смертной казни до введения суда присяжных в Чеченской Республике, в очередной раз отложенного до 2010 года.

Примечательно, что, невзирая на существующую практику неприменения смертной казни, до последнего времени в Европейском суде по правам человека рассматривались дела, связанные с возможностью назначения исключительной меры наказания в России. Так, например, окончательное решение по делу «Шамаев и 12 других против Грузии u России», принятое 12 октября 2005 года, предусматривало обеспечение гарантий запрашивающей стороной с точки зрения неприменения к обвиняемым исключительной меры. Как следовало из текста постановления, 13 чеченцев были задержаны в августе 2002 года грузинскими пограничниками по обвинению в незаконном пересечении границы. Впоследствии российские власти потребовали выдать задержанных по подозрению в причастности к деятельности незаконных вооруженных формирований на территории Чеченской Республики, не предоставив исчерпывающих доказательств этого обвинения. При этом в России против заявителей было возбуждено уголовное дело по обвинению в посягательстве на жизнь сотрудников правоохранительных органов ${ }^{25}$. Несмотря на это, пятеро задержанных были выданы России, а еще двое были немногим позже арестованы властями Российской Федерации после их исчезновения из Тбилиси в феврале 2004 года и помещены в следственный изолятор в Ессентуках. Однако на момент разбирательства данного дела в России уже почти 10 лет не применялась смертная казнь. Тем не менее представители заявителей ставили под сомнение факт действительности предоставленных гарантий. В качестве аргумента было отмечено, что упомянутый Указ Президента, на который ссылалась российская сторона, ни в одном из своих положений не регулирует вопросы моратория, а всего лишь обязывает правительство «подготовить для внесения в Государственную Думу ... проект федерального закона о присоединении Российской Федерации к Протоколу № 6» ${ }^{26}$. Речь, таким образом, велась не о моратории, а о временной мере, касающейся непосредственно применения смертной казни и сокращения оснований для ее применения. Однако данная аргументация была отвергнута Судом, указавшим, что

25 Одно из нескольких преступлений, за которое в ст. 317 УК РФ предусмотрено наказание в виде пожизненного заключения или смертной казни.

26 П. 1 Указа Президента РФ от 16.05.1996 № 724. 
данные и.о. Генерального прокурора РФ гарантии являются достаточными, так как «они исходят от Генерального прокурора, наделенного полномочиями контроля над деятельностью всех прокуроров Российской Федерации» ${ }^{27}$. Гарантии российской стороны были признаны достаточными, и нарушений в действиях РФ усмотрено не было. Отметим, что заявители также указывали на несостоятельность данного Указа Президента, не упомянув, впрочем, ни о сложившейся практике, ни об упомянутом Постановлении КС РФ, ни тем более об обязательствах РФ перед ПАСЕ по указанным выше основаниям. В заключение отметим, что, помимо указанных выше двух дел, касающихся возможной экстрадиции заявителей из Российской Федерации в третью страну, дело Шамаева и других стало последним рассмотренным в Европейском Суде, непосредственно затрагивающим тему применения смертной казни в Российской Федерации.

На примере рассмотренных выше решений можно сделать вывод, что в настоящее время смертная казнь не рассматривается Европейским судом по правам человека в качестве нарушения ст. 2 ЕКПЧ. То есть смертная казнь действительно может явиться нарушением права на жизнь, однако не непосредственно, а лишь в случаях, когда ее применение противоречит отдельным положениям ст. 2 ЕКПЧ. Как, например, в случае Оджалана, когда речь шла о нарушении положения конвенции о том, что смертный приговор должен быть вынесен судом (подразумевается, что справедливым и легитимным). Таким образом, с одной стороны, Суд не исключает трактовки ст. 2 ЕКПЧ с той точки зрения, что смертная казнь сама по себе является нарушением права человека на жизнь. Вместе с тем, принимая во внимание, что часть государств Европы еще не ратифицировала Протокол № 13, Суд воздержался от того, чтобы признать, что ст. 2 конвенции запрещает смертную казнь в принципе и полагает ее нарушением права человека на жизнь. Между тем на практике лица, приговоренные или имеющие возможность быть приговоренными к смертной казни, все равно не передаются запрашивающему государству (или передаются под соответствующие гарантии), так как данная мера, как правило, признается нарушением ст. $3^{28}$, а также, в указанных выше случаях, ст. 2 ЕКПЧ.

27 Пара 344 Окончательного решения ЕСПЧ по делу «Шамаев и 12 других против Грузии и России» от 12.10.2005.

${ }^{28}$ В отличие от ст. 2 данная статья защищает от пыток и жестокого обращения при любых обстоятельствах и не допускает никаких отклонений или исключений. Кроме 
Что касается современного положения России, то она, на наш взгляд, за последнее время проявила себе как сторонник отказа от смертной казни в мирное время при любых обстоятельствах. Действительно, даже при разбирательстве очень сложных дел, когда тяжелые последствия преступлений были налицо, смертная казнь не назначалась в качестве наказания, вопреки мнению представителей прокуратуры и общественности. Однако смертная казнь по-прежнему регламентируется УК РФ как вид наказания и по-прежнему поддерживается населением, в том числе рядом юристов и общественных деятелей. При этом законодательный статус смертной казни довольно зыбок, а о ратификации Протоколов № 6 и № 13 пока говорят только в будущем времени и с долей скептицизма. Между тем жесткий контроль за вопросами смертной казни в России дополнительно устанавливается с принятием двусторонних соглашений о правовой помощи, регламентирующих, помимо прочего, вопросы выдачи преступников в страны, где им грозит смертная казнь. К примеру, с принятием в 2003 году Протокола к Договору между Российской Федерацией и Социалистической Республикой Вьетнам о правовой помощи статья о невыдаче была дополнена положением о возможном отказе в выдаче в случае, если «преступление, в связи с которым поступил запрос о выдаче, наказывается смертной казнью в соответствии с законодательством запрашивающей ... Стороны и при этом запрашивающая ... Сторона не предоставит ... достаточные гарантии того, что смертный приговор не будет приведен в исполнение» ${ }^{29}$. Как представляется, данный пример подтверждает, во-первых, факт важности для России текущей практики ЕСПЧ, неоднократно использовавшего данный инструмент в своих постановлениях, а во-вторых, общее стремление РФ к отмене смертной казни, к сожалению, пока не вполне оформленное законодательно.

Подводя итоги, можно с сожалением, но с уверенностью отметить, что смертная казнь остается одним из вопросов национального и международного права, по которому единого мнения международному сообществу достичь пока не удалось. Даже существующие

того, в отличие от Протоколов № 6 и № 13, данное положение входит в основной текст ЕКПЧ и признается всеми государствами, подписавшими ее.

29 Ст. 1 Протокола к Договору между Российской Федерацией и Социалистической Республикой Вьетнам о правовой помощи и правовых отношениях по гражданским и уголовным делам от 23.07.2003. 
международно-правовые положения регионального характера (в частности, Европейской конвенции о защите прав человека и основных свобод) весьма осторожно толкуются органами правосудия с точки зрения взаимосвязи изучаемого явления с правом человека на жизнь, закрепленным в нормативно-правовых актах как национального, так и международного характера.

В связи с вышесказанным представляется особенно важным четко регламентировать смертную казнь с точки зрения ее взаимосвязи с правом человека на жизнь. В данном случае имеется в виду недвусмысленная позиция международных органов по вопросу, считать ли смертную казнь нарушением указанного права или нет. Действующие сегодня международно-правовые акты и судебные решения не выражают четкой позиции в данном отношении применительно к наиболее общим случаям, что представляется некоторым упущением. Решение вопроca, в частности, состоит в многостороннем и полном изучении и анализе практики судов как национального, так и международного уровня. Очевидно, что особое место в формировании современного понимания смертной казни занимают решения Европейского суда по правам человека. Как представляется, Суд затрагивает наиболее спорные вопросы применения смертной казни, в частности вопросы экстрадиции лиц в страны, где к ним может быть применена смертная казнь, вопросы ожидания смертной казни вообще и условий содержания приговоренных в частности. В настоящее время ЕСПЧ в подобных случаях действует преимущественно по правилам судебного прецедента (а также основывается на ряде региональных актов, например упомянутой Европейской конвенции о выдаче), однако официальное нормативное закрепление смогло бы существенно упростить разбирательство подобных дел и до возможной степени уменьшить количество спорных ситуаций по данным вопросам. Пока же данные вопросы регулируются преимущественно внутренним правом, двусторонними договорами, а также решениями судов по конкретным случаям.

На основе вышесказанного представляется, что признание смертной казни незаконной в глобальном масштабе сегодня представляется несколько преждевременным. Более того, едва ли возможно даже принятие некоего перечня преступлений, караемых данным наказанием. Это обусловлено целым рядом факторов: и слишком разными представлениями об опасности тех или иных деяний, и общим нежеланием ряда ключевых стран принимать на себя какие-либо правовые 
ограничения, и возможными дискуссиями по вопросу степени влияния международного права на право внутреннее. При этом европейские и другие страны, отказавшиеся от смертной казни, могут лишь дополнительно подтвердить свою позицию в отношении исключительной меры наказания, в том числе в дальнейшей практике Европейского суда.

Таким образом, несмотря на видимую тенденцию к отмене смертной казни с минимальными исключениями (согласимся здесь с мнением Б.Р. Тузмухамедова ${ }^{30}$ ), на наш взгляд, на данном этапе развития общества смертная казнь имеет право на существование для применения в определенных случаях, что обусловлено не только высоким уровнем преступности в ряде стран, в том числе в России, но и увеличением количества преступлений, связанных с угрозой для жизни большого количества людей (в первую очередь случаев терроризма). Для таких преступлений исключительная мера наказания представляется допустимой при условии тщзательнейшего судебного разбирательства, а также несомненности вины обвиняемых. Каждый случай должен рассматриваться особо с учетом всех имеющихся обстоятельств, в том числе морально-этических аспектов, с тем чтобы до максимально возможной степени исключить вероятность судебной ошибки. При этом должна быть существенно усилена роль международного права в регулировании отдельных вопросов назначения и применения данного наказания (перечень преступлений, условия содержания, экстрадиции и проч.). При этом вопрос о том, до какой степени нормы международного права и практика международных судов могут оказывать влияние на решение внутригосударственного суда, естественно, находится в юрисдикции самого государства. Однако в условиях глобализации игнорировать роль международного права и позицию международных органов правосудия в отношении приоритетного права каждого человека - права на жизнь - представляется просто неразумным. Именно в случае активного взаимодействия всех заинтересованных субъектов возможно достижение результата, максимально приемлемого всеми сторонами. И в этом случае практика судов играет двоякую роль: с одной стороны, предвосхищая ту или иную норму, возникающую из результатов практики судов, а с другой - закрепляя вновь созданную норму права на практике, в судебных разбирательствах.

30 Б.Р. Тузмухамедов. Указ. соч. С. 55. 
Вместе с тем, несмотря на существующие результаты исследований, доказывающих эффективность смертной казни ${ }^{31}$, представляется, что более эффективным и безболезненным способом борьбы с преступностью является не ужесточение наказаний, а улучшение мер по предотвращению преступлений, а также усиление мероприятий по их скорейшему раскрытию. Неотвратимость наказания, которое обязательно наступит (причем совсем необязательно смертной казни), как представляется, является гораздо более эффективным психологическим средством борьбы с преступностью, чем жесткость того наказания, которое может наступить. В этом плане наиболее эффективным инструментом стало бы усиление мер, направленных на предотвращение или скорейшее раскрытие уже совершенных преступлений, как на национальном, так и на международном уровне.

\section{Библиографический список}

Европейский суд по правам человека и Российская Федерация. Дело «Илашку и другие против Молдавии и Российской Федерации». Документы и материалы». Администрация Президента Российской Федерации. М., 2006.

Мезяев А.Б. Проблема смертной казни в региональном международном праве (опыт Европы, Америки и Азии) // Московский журнал международного права. № 2/2001.

Мезяев А.Б. Смертная казнь и прогрессивное развитие современного международного права // Юрист-международник. № 4/2003.

Тузмухамедов Б.Р. Отмена смертной казни в России: международные обязательства и конституционная юрисдикция // Международное право. № 4/2008.

Adler R., Summers M. Capital punishment works // The Wall Street Journal, 02.11.2007.

${ }^{31}$ См., напр.: Adler R., Summers M. Capital punishment works // The Wall Street Journal, 02.11.2007. 


\section{Death Penalty and Right to Life (Summary)}

\section{Ivan S. Semyonov*}

The article dwells on the contemporary situation in respect of the judicial practice related to the application of the capital punishment both in international and national law. Today the European Convention for the $\mathrm{Hu}-$ man Rights is the only international Act, prohibiting the death penalty as per Protocols № 6 and № 13. The author has undertaken an attempt to analyze the current situation, basing on the recent judgments of the European Court. However, the Court still has no definite opinion regarding the subject - should the capital punishment be considered as a violation of the Art. 2 of the Convention or not. The current cases mostly correlate the possibility of the application of the capital punishment with Art. 3 of the Convention, whereas the Art. 2 is considered violated just in some specific cases.

Keywords: right to life; death penalty; European Convention on Human Rights; European court of human rights; protection from torture; extradition.

\footnotetext{
* Ivan S. Semyonov - post-graduate student of the Diplomatic Academy, MFA Russia. i-semenov@inbox.ru.
} 